\title{
O sindicato dos trabalhadores rurais, a comissão pastoral da terra e a luta dos expropriados da Itaipu em Guaíra/PR durante aos anos de 1975 e 1990.
} Ana Paula Lenhardt ${ }^{1}$

Este trabalho é resultado da leitura de uma monografia intitulada "O Sindicato dos Trabalhadores Rurais, a Comissão Pastoral da Terra, e a luta dos expropriados da Itaipu em Guaíra/PR (1751990)". Este Trabalho de Conclusão de Curso foi produzido por Simone de Souza Côrrea ${ }^{2}$ e defendida no ano de 2013.

Os anos que decorrem entre as décadas de 1970 e 1990 são marcados por vários conflitos de terras e fronteiras no extremo Oeste paranaense. Diante desses conflitos percebe-se uma forte participação e luta dos sindicatos dos trabalhadores rurais e dos expropriados pela Usina Binacional de Itaipu na cidade de Guaíra, localizada no Oeste paranaense.

Nesse processo destaca-se também o papel exercido pela Comissão Pastoral da Terra - CPT, das mídias locais que difundiam um discurso oficial a respeito das manifestações realizadas pelo Sindicato

\footnotetext{
${ }^{1}$ Acadêmica do $4^{\circ}$ ano de História da Universidade Estadual do Oeste do Paraná UNIOESTE Campus Marechal Cândido Rondon, Centro de Ciências Humanas Educação e Letras - CCHEL.

2 Simone Côrrea ex-acadêmica do Curso de História da UNIOESTE Campus Marechal Cândido Rondon.
} 
dos Trabalhadores Rurais contra a construção da Itaipu e do posicionamento do governo militar diante das manifestações dos expropriados da Guaíra.

$\mathrm{Na}$ primeira parte do trabalho a autora da monografia busca apresentar um breve histórico da cidade de Guaíra em relação as disputas de poder e território. Destaca-se que o Oeste do Paraná sempre foi um palco de disputas, sejam elas territoriais ou políticas. $\mathrm{O}$ território paranaense passou a ser ocupado mais intensivamente durante a Primeira Republica (1889-1930), nesse período houve grande número de concessões de terras feitas por parte do Governo Federal que pretendia ocupar os "vazios demográficos". Tais concessões eram baseadas na Lei de Terras de $n^{\circ}$ 98/1892 que visava a concessões de terras para obras públicas e também para localização de colonos.

Porém, as concessões feitas favoreceram empresas estrangeiras que ocuparam a região e desenvolveram atividades extrativistas e que pouco contribuíram para a colonização da região do extremo Oeste paranaense, tais empresas, em sua maioria argentinas e paraguaias, que ocuparam a região ficaram conhecidas como obrages $^{3}$.

Além da instalação das obrages no território brasileiro, outras demarcações de terra foram feitas na região, foram elas, a Companhia de Estrado de Ferro São Paulo-Rio Grande e a Colônia Militar de Foz do Iguaçu, instalada por razão de defesa do território e de cobrança de

\footnotetext{
${ }^{3}$ As obrages eram fazendas que tinham características próprias, elas se instalavam em regiões próximas de rios e desenvolviam um sistema portuário por onde escoavam sua produção baseada no extrativismo, principalmente da erva-mate e da madeira.
} 
impostos. Nesse sentido, pode-se pensar que a ocupação do território Oeste paranaense, não se deu pela colonização de migrantes somente, mas também, pela disputa de território.

A colonização da região de Guaíra aconteceu principalmente a partir da instalação da Companhia Mate Laranjeira que foi instalada em 1902 (na região de Guaíra) no território que demarca a fronteira brasileira com o Paraguai. A Mate Laranjeira teve importante papel na região, esta empresa de capital estrangeiro foi construída durante o desdobramento da Guerra do Paraguai. Além disso, ela deu apoio ao exército imperial brasileiro, destinando a ele mantimentos e armamentos e por esse motivo, obtiveram várias vantagens, entre elas concessões de terras para exploração de erva-mate e madeira na região na qual estava situada, além de incentivos fiscais.

Diante disso, pode-se perceber a importância política que a Companhia Mate Laranjeira possuía, não apenas na região, para conseguir concessões de terras, acordos e benefícios, e poder econômico para conseguir melhorias nas estruturas das áreas adquiridas pela empresa, é por essas características que esta empresa era considerada umas das maiores obrages da região da bacia do Prata.

No que se diz respeito à colonização do extremo Oeste, as disputas dos territórios e fronteiras se deram desde a formação dos estados nacionais até o estabelecimento das fronteiras pelo tratado de Madrid. Porém, as obrages que existiam na região não respeitavam os limites de fronteira estabelecidos por esse tratado e prosseguiam 
explorando as terras do território brasileiro, fator que levou a instalação da Colônia Militar em Foz do Iguaçu. No entanto, os militares instalados em Foz do Iguaçu atuavam como milícias que davam suporte e fiscalizavam o trabalho dos mensus $^{4}$ para os obrageros ${ }^{5}$.

A Mate Laranjeira tinha um forte controle de sua mão de obra, não apenas realizado pelo capatazes ou pelas milícias, mas exercida também pela força e ameaças vindas dos obrageros. Encontra-se no conhecimento popular histórias de execuções e também de funcionários jogados no rio Paraná por desobediência. Essas medidas e também o controle do uso de armamento, bebidas alcoólicas, jogos e o "toque de recolher" garantiam uma alta exploração e controle sobre os trabalhadores.

Esse poder exercido pelas obrages no interior do Paraná, motivou o desenvolvimento da campanha da Marcha para o Oeste desenvolvida, durante o Estado Novo (1937-1945). Esta campanha tinha por objetivo a nacionalização e desenvolvimento das regiões do extremo Oeste paranaense e também do Centro-Oeste brasileiro.

O controle desenvolvido pela Mate Larangeira e também seu desenvolvimento econômico chegaram ao conhecimento de Vargas. Em 17 de abril de 1942, sob o Decreto n 6428/42, o Governo de Vargas encampou todo o transporte ferroviário e hidroviário da localidade,

\footnotetext{
${ }^{4}$ Mensus eram os trabalhadores das obrages, em sua maioria eram caboclos, descendentes ou indígenas da região, trabalhavam em condições análogas a escravidão.

${ }^{5}$ Donos das obrages
} 
inclusive os pertencentes à Mate Laranjeira que perdeu todas suas posses. Assim, todas as posses foram passadas ao Serviço de Navegação da Bacia do Prata (SNBP), subsidiado pelo Ministério de Viação e Obras Públicas, que visava dar continuidade na exploração da erva-mate e outras atividades antes realizadas pela Companhia estrangeira na região.

O Serviço de Navegação da Bacia do Prata (SNBP) foi extinto em 1967, pelo Decreto-Lei no 154 , de 10 de fevereiro de 1967, que foi estabelecido diante do desenvolvimento das atividades ervateiras argentinas e pela concorrência do mercado brasileiro e consequentemente desvalorização da cultura que já não resultava nos lucros esperados pelo governo. Com final do ciclo da erva-mate, principalmente na região de Guaíra, os moradores da região, se viram obrigados a buscar outras atividades.

Nessa busca por alternativas os habitantes de Guaíra bem como migrantes de várias regiões do país, como Minas Gerais, São Paulo e Bahia, vinham para o Paraná motivados pela terra fértil e seu baixo preço para o desenvolvimento da agricultura. Essa busca por terras causou novos conflitos, esse fator desencadeou na fundação do Sindicato dos Trabalhadores Rurais ${ }^{6}$ (não confundir com o Patronal) que visava resolver as questões referentes à demarcação de terras e conflitos agrários.

${ }^{6}$ Sindicato formado por pequenos proprietários, trabalhadores, meeiros, posseiros, boias-frias, entre outros. 
Além desses conflitos, o sindicato precisou resolver o problema interno referente ao assistencialismo que dificultou a articulação dos membros referentes ao apoio aos trabalhadores, tanto na terra quanto no trabalho no campo, fator que inviabilizava a articulação e a luta dos trabalhadores rurais.

Com o aumento dos sindicalizados o sindicato não conseguia dar assistência a todos. A partir de 1986 o sindicato conseguiu ir além do assistencialismo após a eleição da nova diretoria que tornou o sindicato mais combativo e menos assistencialista. $\mathrm{O}$ sindicato passou a ter pautas mais reivindicativas e também se filiou a CUT (Central Única dos Trabalhadores). Promoveram e participaram de passeatas e lutas locais e nacionais, passaram também a discutir políticas de Reforma Agrária e a participação popular, direitos e deveres dos agricultores diante da nova Constituição de 1988.

As lutas do Sindicato juntamente com os expropriados da Itaipu ocorreram num contexto de disputa de fronteiras e territórios, poder político e econômico, bem como de repressão da população que já ocorria desde a época da Companhia Mate Laranjeira e que se intensificou no período da Ditadura Civil Militar. Em suma, o trabalho realizado pelo Sindicato era dar apoio ao agricultor familiar para que ele pudesse se manter na terra, e isso significava, não apenas ter a propriedade, mas sim a preservação de uma cultura e modo de vida.

Após a realizar um breve histórico da colonização do município de Guaíra e também do Sindicato dos Trabalhadores Rurais, 
na segunda parte da monografia Simone Corrêa buscou discutir o envolvimento do Sindicato dos Trabalhadores Rurais com a Comissão da Pastoral da Terra e também do Movimento dos Expropriados de Itaipu. A autora inicia referenciando a década de 1970, conhecida no Brasil pelo "Milagre Econômico" e pelas construções de grandes complexos industriais e grandes obras como a Usina Binacional de Itaipu bem como pela repressão aos movimentos sociais. A construção da represa da referida usina gerou um grande número de expropriações e também o fim das Sete Quedas, fato esse que marcou fortemente os habitantes da cidade de Guaíra, pois as Sete Quedas eram um ponto turístico que trazia ao município um grande valor turístico e financeiro. Além de inundarem as Sete Quedas, as águas da represa atingiram parcialmente os municípios paranaenses de Foz do Iguaçu, São Miguel do Iguaçu, Medianeira, Matelândia, Santa Helena, Marechal Cândido Rondon, Guaíra e Terra Roxa do Oeste. Diante disso, a formação do lago de Itaipu causou além das transformações ecológicas e seus consequentes problemas, o problema social da terra, pois muitos agricultores perderam suas terras, casas e posses.

Perante isso, passou a se desenvolver na região várias lutas sociais na busca de indenizações, surgiram assim os movimentos Justiça e Terra (1978), Movimento dos Agricultores sem Terra do Oeste do Paraná - MASTRO (1980), e o Movimento Sem Terra - MST (1984). Ao longo dessas lutas surgiram vários líderes sindicais e religiosos, os quais se vinculavam a Comissão Pastoral da Terra (CPT). A CPT foi 
fundada em 1985 no Congresso Nacional da Comissão Nacional dos Bispos do Brasil (CNBB) em Goiânia-GO. Esta entidade foi fundada durante a Ditadura Civil Militar em resposta à grave situação dos camponeses brasileiros.

As consequências da construção de Itaipu são grandes, em relação às expropriações são cerca de 400 propriedades rurais que foram atingidas e 10,30\% do território do município. No que diz respeito a algumas leituras feitas sobre o processo que definem que os habitantes de Guaíra foram passivos em relação aos processos decorrentes da construção da Usina de Itaipu, a autora destaca que, na prática, esta passividade não aconteceu, pois foram muitas as ações e manifestações realizadas no período pelos grupos que foram diretamente atingidos pela construção. Contudo, também deve-se levar em conta que o município de Guaíra estava situado uma região considerada área de segurança nacional devido à sua localização fronteiriça, logo, um espaço que estava sob constante vigília do governo militar brasileiro, fato que tornava essas mobilizações e as pessoas nelas envolvidas alvos diretos de perseguição, mas não impediu a luta.

Durante esse período, circulavam na mídia notícias que ocultavam as manifestações populares contra a Usina de Itaipu e pelas indenizações justas de terras, além disso, circulavam notícias que desinformavam parte da população sobre o real projeto de Itaipu. Assim, é importante enfatizar que os habitantes de Guaíra não eram passivos aos acontecimentos, pois houve manifestações contra a 
construção da Usina de Itaipu e também movimentos de luta junto aos expropriados de Itaipu, mas a mídia censurou essas manifestações a fim de manter o controle da população e dos movimentos de apoio à causa não aumentarem.

Deve-se ainda enfatizar que maioria dos expropriados não eram latifundiários nem afortunados, mas pequenos agricultores que tinham seu sustento na agricultura familiar. Muitos tiveram que abandonar suas casas antes do previsto pela mudança do curso do rio Paraná, que devastou tudo o que ficou para trás.

O descaso da Itaipu para com essas pessoas foi algo sem explicação, houve desde o não comprimento das indenizações e indenizações injustas até a valorização dos animais para a reserva de Itaipu, e a desvalorização do homem diante da tragédia que ocorreu em suas vidas por conta da construção da Usina.

Nesse sentido, pensa-se que a Itaipu representou o poder das elites, as vantagens se deram apenas para esses sujeitos mais abastados da sociedade e os prejuízos foram redirecionados para os desfavorecidos, no caso os expropriados. Porém dessa desigualdade surgiram os movimentos sociais, liderados por pequenos agricultores, sindicalistas e algumas entidades religiosas, que se opuseram a tal situação. História ainda pouco conhecida, mas de grande importância para se compreender o processo de construção da região oeste do Paraná. 
Referências

CORRÊA, Simone de Souza. O Sindicato dos Trabalhadores Rurais, a Comissão Pastoral da terra, e a luta dos expropriados da Itaipu em Guaíra/PR (175-1990) (Monografia). Marechal Cândido Rondon, 2013. 